Cadernos de Clio, Curitiba, v. 12, $\mathrm{n}^{\circ} .1,2021$

\title{
MULAN DE 1998 E 2020: OS ESTEREÓTIPOS, ORIENTALISMOS E NARRATIVAS DA CULTURA ASIÁTICA QUE PERMANECERAM APÓS 22 ANOS
}

Marcela Langer ${ }^{1}$

A partir de uma análise comparativa entre o filme de animação Mulan, de 1998, e sua versão live-action de mesmo nome lançada em 2020, faz-se possível uma abordagem crítica quanto aos aspectos centrais das duas produções, em questões de narrativa, representações e estereótipos em relação à região do Leste Asiático. Além disso, propõe-se uma reflexão acerca da companhia produtora responsável, Walt Disney Pictures, e sua intrínseca relação com a escolha de discursos sobre a China, local pelo qual se passam as histórias.

O primeiro filme, de 1998, tem como diretores os norte-americanos Tony Bancroft, da Califórnia, e Barry Cook, do Tennessee, que basearam-se na história apresentada pelo também californiano Robert D. San Souci, responsável por escrevê-la para a animação. Já a versão lançada em 2020 foi embasada na obra secular de Hua Mulan, sendo dirigida pela neozelandesa Niki Caro, contando com um elenco majoritariamente chinês e dando destaque para a atriz sino-americana Liu Yifei, que interpretou a protagonista. Em ambas as histórias, a síntese é a mesma: se trata da filha mais velha, a jovem Mulan, que vai no lugar do pai, um antigo guerreiro,

${ }^{1}$ Graduanda em História (Licenciatura/Bacharelado) pela Universidade Federal do Paraná (UFPR). Email para contato: langer403@gmail.com. Endereço para o Currículo Lattes: http://lattes.cnpq.br/4319850110188500. 
porém agora doente, quando o Imperador chinês decreta que um homem de cada família deve se alistar ao exército imperial. Assim, sob o nome de Hua Jun, Mulan se disfarça de homem para defender sua nação do ataque invasor, demonstrando ter talento e aspiração para ser uma grande guerreira.

Primeiramente, faz-se necessário uma contextualização acerca da companhia Walt Disney Pictures, responsável pela produção do filme. A partir do artigo das autoras Manuela Aguiar e Bárbara Arruda, é explicitado que a empresa norte-americana é uma das principais responsáveis na dominação da cultura popular nos Estados Unidos, e, por um dos seus principais veículos ser as produções de filmes infanto-juvenis, esse domínio parte das mentalidades (AGUIAR; ARRUDA, 2019: 6). Além disso, as autoras também destacam, a partir de colocações do professor de estudo de mídia Lee Artz, que a Disney passou de uma simples produtora de filmes para uma "educadora moral americana", tendo em vista que, através dos desenhos, consegue-se difundir ideologias não apenas em território estadunidense como no mundo todo (AGUIAR; ARRUDA, 2019).

Com isso, no tocante às versões de Mulan, tanto a animação em desenho quanto no live-action, pode-se constatar a escolha de uma narrativa acerca da China, local em que se passa a história, que tem como curso ideológico a propagação de estereótipos não apenas chineses, mas do leste asiático como um todo. Esses estereótipos, antes de tudo, podem ser interpretados como uma ferramenta integrante do discurso colonial, a qual, segundo a obra de Homi K. Bhabha, apresenta-se como a principal 
estratégia discursiva desse discurso, tornando-se uma forma de conhecimento e identificação que oscila entre estar sempre imutável, ao passo que é frequentemente repetido (BHABHA, 1998: 5). Em ambas as versões de Mulan, essa perpetuidade é apresentada na ausência de temporalidade pelo qual se passam as produções. Desse modo, em conjunto com o discurso colonial, insere-se a imagem de uma China parada no tempo, como observa David Martínez-Robles, que argumenta que, desde os tempos medievais, a China é alvo de características místicas no imaginário europeu, reproduzidas através de vestígios de um passado distante, constituindo uma nação sem presente, pertencendo a uma cultura morta (MARTÍNEZ-ROBLES, 2008: 4).

Com isso, tal mentalidade pode ser vista principalmente na versão animada de Mulan, em que a presença de animais folclóricos chineses, a constante menção aos ancestrais e a representação do imperador que se comunica através de valores sábios constituem o imaginário estereotipado de uma China mística, prendida ao passado e com uma cultura que remete apenas a elementos antigos, ainda que nenhuma das versões de Mulan define a temporalidade pelo qual a história se passa. Com o artigo do autor Zhao Gengcheng, da Universidade de Estudos Estrangeiros de Pequim, constata-se que o filme Mulan é um típico caso de orientalismo que opõe leste contra oeste, além de estigmatizar a China e distorcer seu folclore tradicional (GENGCHENG, 2020: 2). O autor Edward Said constata que o Oriente não é um fato inerte da natureza, sendo uma ideia que tem história, tradição de pensamento, imagens e vocabulário partidos do e para o 
Ocidente, sendo, portanto, duas entidades que se apoiam e se refletem, sendo uma relação que parte de dominação e poder (SAID, 1996: 16-17).

A partir do artigo de Aguiar e Arruda, é explanado acerca das técnicas gráficas nas animações da Disney que são utilizadas como meio de distinguir o bem e o mal, seja através de personagens humanos ou do reino animal. Esse dualismo deriva da sociedade cristã, que prega o que é certo e errado a partir das condutas éticas e morais do Ocidente. Nos desenhos da Disney, personagens do bem irão conter traços juvenis, desenhados de maneira suave e iluminados, possuindo características europeias, enquanto que nos personagens malvados os ângulos são afiados em tons maiores que o padrão e, em sua grande maioria, representados por tons mais escuros (AGUIAR; ARRUDA, 2019: 3-7). Essas representações se concretizam na versão animada de Mulan, tendo em vista que os invasores são ilustrados como personagens de paleta escurecida. Além disso, a personagem Mulan possui tom de pele mais claro quando em comparação aos personagens coadjuvantes, a exemplo do seu colega guerreiro Li Shang, que apresenta tons mais próximos do amarelo, evidenciando, assim, características europeias para uma personagem oriental. Desse modo, explicitam-se narrativas e representações imagéticas de caráter ocidental, mesmo tratando-se de aspectos de uma cultura diferente, apontando o que Said explica como que para um europeu ou americano que esteja estudando sobre o Oriente, não há a possibilidade da negação de sua própria realidade, sendo que primeiramente chega-se ao Oriente como alguém oriundo da Europa ou dos Estados Unidos, e depois como indivíduo (SAID, 1996: 23). 
Retornando ao campo dos estereótipos, Homi K. Bhabha aponta que o discurso colonial é uma realidade social que funciona como o "outro" e também como algo apreensível e visível, ou seja, segue uma narrativa cuja produtividade, circulação e signos são agregados de maneira reformulada e reconhecível, formando um sistema de representação que se aproxima do real. Com isso, Bhabha define o estereótipo como ponto primário no discurso colonial, que mira entre fantasia e semelhança na procura de uma originalidade, ainda que seja limitada pelas distinções de raça, cor e cultura. Assim, o autor afirma que o estereótipo é uma simplificação, não devido a sua falsa representação da realidade, mas sim a sua maneira presa e fixa de representação, que nega a diferença, singularidade esta que o "outro" permite, a partir de sua negação (BHABHA, 1998: 11-17). Com base nisso, na versão Mulan de 1998, nota-se que os estereótipos permeiam todo o filme, principalmente com a presença dos personagens do dragão Mushu e do grilo Gri-Li. A versão live-action de 2020 não contém suas aparições, porém ainda assim é retratada a questão de honra, tanto para o casamento de Mulan quanto para salvar a China das invasões, o que também é presente na versão animada. Assim, nota-se que apesar da versão de 2020 não conter tantos adereços estereotipados quanto no desenho, a narrativa de honra e ancestralidade são essenciais no filme, permanecendo a visão de uma China presa ao passado.

Por fim, o que resulta da tentativa da Disney ao refazer Mulan, cuja primeira versão recebeu duras críticas por parte dos chineses, infelizmente também não foi muito promissor. Para além de ter dado prejuízo para a 
produtora -- a bilheteria foi de US $\$ 70$ milhões, enquanto o orçamento foi de US \$200 milhões, o que se justifica pelos muitos cinemas ao redor do mundo fechados por conta da pandemia de Covid-19 - a forma escolhida para recontar uma história já conhecida pouco agradou, dessa vez não apenas aos chineses. Ainda que a produtora tenha trazido maior representatividade ao filme, escolhendo Liu Yifei para o papel de Mulan, a história apresenta dificuldade em se conectar. Mesmo retirando Mushu, Gri-li e as músicas, a sensação que fica é de que a Disney ainda não conseguiu produzir uma história sobre um povo, senão o seu próprio. Sob a tentativa de fugir dos estereótipos, se frustra com a não alternativa para tal. Dessa forma, pontuam-se as principais características de Mulan, tanto a de 1998 quanto a de 2020: o discurso colonial da China como uma cultura ligada ao passado, o olhar estereotipado de sua cultura e a Disney enquanto disseminadora do discurso orientalista. Por fim, mesmo tendo uma diferença de mais de 20 anos entre uma versão e outra, e ainda assim a narrativa orientalista permanecer, demonstra como o orientalismo não apenas cria, mas também mantém - ele controla, manipula e incorpora um mundo que não é seu (SAID, 1996: 24).

\section{Referências}

ARRUDA, Bárbara A.; AGUIAR, Manuela A. Aladdin, Noites da Arábia e uma proposta de estudo sobre o Oriente produzido pela Walt Disney Company. 2019. Disponível em: $<$ https:/www.academia.edu/43631375/ALADDIN_NOITES_DA_AR\%C3 $\% 81 B I A$ E_UMA_PROPOSTA_DE_ESTUDO_SOBRE_O_ORIENTE_P 
RODUZIDO_PELA_WALT_DISNEY_COMPANY>. Acesso em: 25 fev. 2021.

BHABHA, Homi K. O Local da Cultura. Belo Horizonte: Editora UFMG, 1998.

GENGCHENG, Zhao. American Mulan: Powerful and Powerless, 2020. Disponível em:

$<$ https://uscet.net/doc/Zhao\%20Gengcheng\%20-\%20American\%20Mulan \%20-\%20Powerful\%20and\%20Powerless.pdf>. Acesso em 25 fev. 2021.

MARTÍNEZ-ROBLES, David. The Western Representation of Modern China: Orientalism, Culturalism and Historiographical Criticism. Digithum, n. $10, \quad$ maio 2008 Disponível em: $<$ http://www.uoc.edu/digithum/10/dt/eng/martinez.pdf $>$. Acesso em: 25 fev. 2021.

SAID, Edward W. Orientalismo: O Oriente como invenção do Ocidente. São Paulo: Companhia das Letras, 1996.

Recebido em: 23/05/2021 Aceito em: 30/09/2021 